\title{
Perancangan Mobil Penjual Obat (Apotek Berjalan) serta \\ Sistem Informasi Manajemen Ketersediaan Obat-obatan Berdasarkan Aspek Ergonomi Mikro dan Ergonomi Makro
}

\author{
Designing Drug Selling Car And Information System for Medicines \\ Management Based on Micro Ergonomic and Macro Ergonomic Aspects
}

\author{
Wawan Yudiantyo, Ninie Agustin \\ Prodi Teknik Industri, Universitas Kristen Maranatha \\ E-mail: wawanyudiantyo@yahoo.com,ninieagustin@gmail.com
}

\begin{abstract}
Abstrak
Fasilitas kesehatan merupakan sebuah fasilitas yang penting diberikan kepada masyarakat secara merata dan menyeluruh. Salah satu fasilitas kesehatan ialah penyediaan obat-obatan yang diperlukan masyarakat. Keberadaan apotek di kota-kota sangatlah banyak. Masyarakat bisa dengan mudah mendapatkan obat-obatan yang diperlukan di perkotaan. Akan tetapi, jika dicermati, keberadaan apotek atau rumah obat di daerah terpencil atau pedesaan sangatlah kurang atau tidak ada. Ketersediaan obat di warung-warung hanyalah obat yang bersifat umum, tapi obat-obatan yang harus diperoleh dari resep yang dikeluarkan dokter sangatlah minim. Puskesmas biasanya hanya menyediakan obat-obatan jatah dari pemerintah, tidak dengan obat racikan yang biasanya diberikan dalam resep dokter.

Berdasarkan permasalahan di atas, maka akan dirancang ulang sebuah mobil yang dimodifikasi menjadi sebuah toko obat berjalan (apotek berjalan), yang mana bisa menjangkau pedesaan, dalam menyalurkan obat-obatan secara lebih lengkap. Rekayasa perancangan mobil meliputi perancangan tata letak, ruang peracikan, fasilitas penyimpanan obat-obatan, dan sistem informasi penyimpanan obat-obatan. Semuanya ini didekati dengan aspek keilmuan ergonomi mikro dan ergonomi makro. Dari segi ergonomi mikro, akan dirancang segala fasilitas fisik dan lingkungan fisik kerja. Sedangkan dari segi ergonomi makro, dengan adanya fasilitas ini, kesejahteraan dan keterjaminan masyarakat akan kesehatan akan lebih terjamin dan luas sampai ke pelosok desa.
\end{abstract}

Kata Kunci: ergonomi makro, ergonomi mikro, mobil apotek, sistem informasi obat-obatan

\begin{abstract}
Health facility is an important facility provided to the community evenly and thoroughly. One of the health facilities is the provision of medicines needed by the community. There are many pharmacies in the cities. People can easily get the medicines they need in urban areas. However, if we look closely, the existence of pharmacies or medicinal houses in remote or rural areas is lacking or non-existent. The availability of drugs in the stalls (small store in village) is only general medicine, but the medicines that must be obtained from a doctor's prescription are very less. "Puskesmas" usually only provide medicines rationed by the government, not with the concoction drugs that are usually given in a doctor's prescription.

Based on the above problems, a car that is modified into a mobile drugstore (mobile pharmacy) will be redesigned, which can reach villages, in a more complete way to distribute medicines. Car design engineering includes layout design, compounding rooms, drug storage facilities and drug storage information systems. And all of this is approached with scientific aspects of micro ergonomics and macro ergonomics. In terms of micro ergonomics, all physical facilities and physical work environments will be designed. Meanwhile, in terms of macro ergonomics, with this facility, the welfare and health of the community will be more secure and will extend to remote villages.
\end{abstract}

Keywords: macro ergonomics, medicine information systems, micro ergonomics, mobile drugstore 


\section{Pendahuluan}

Kesehatan merupakan sebuah kebutuhan yang penting dalam kehidupan manusia. Di sisi lain, manusia tidak luput dari sakit penyakit. Di kota-kota besar banyak ditemui fasilitas kesehatan, diantaranya tempat praktik dokter dan apotek/rumah obat. Akan tetapi, tidak begitu keadaannya bila kita tinjau keberadaannya di pinggiran kota atau desa-desa yang jauh dari kota. Untuk mendapatkan perawatan dokter, pemerintah melalui departemen kesehatan menempatkan dokter untuk bertugas di desa-desa. Akan tetapi, mengenai keberadaan obat mempunyai kecenderungan adanya keterbatasan baik dari jumlah maupun jenisnya.

Penelitian ini didasarkan pada kebutuhan adanya sebuah fasilitas atau moda transportasi untuk penyediaan obat, baik obat umum maupun resep untuk daerah pedesaan, yang keberadaannya jauh dari kota. Sebuah mobil barang akan direkayasa untuk dijadikan sebuah fasilitas penjualan dan penyediaan obat laksana apotek berjalan.

Perancangan tersebut meliputi perancangan fasilitas fisik (lemari, meja), tata letak, lingkungan fisik kerja, dan manajemen klasifikasi obat agar mudah untuk dicari. Selain itu, dirancang suatu fasilitas fisik yang akan memudahkan operator dalam mengambil obat-obatan, serta aspek kenyamanan dalam melakukan pekerjaan di dalam mobil tersebut.

Tujuan dari penelitian ini ialah membuat sebuah rancangan mobil sebagai apotek berjalan dalam membantu masyarakat pedesaan mendapatkan obat-obatan yang diperlukan dengan lebih mudah. Perancangan fasilitas penyimpanan obat-obatan, fasilitas ruang peracikan obat, tata letak fasilitas, lingkungan fisik, dan tempat pembayaran pembelian obat. Serta, membuat sistem informasi manajemen yang memudahkan pengelola mobil "apotek berjalan" dalam ketersediaan obat-obatan yang meliputi daftar ketersediaan obat jadi, sistem penyimpanan, sistem palabelan, dan kartu stock obat.

\section{Tinjauan pustaka}

Ergonomi, sebuah ilmu yang sistematis yang menggunakan data-data mengenai sifat, keterbatasan, dan kemampuan manusia dalam merancang suatu sistem kerja, supaya manusia dapat bekerja dalam sistem tersebut secara optimal dalam arti baik, aman, nyaman, tepat, mudah, dan memberikan kepuasan. Baik dalam arti memberikan manfaat pada kehidupan manusia. Aman dalam arti memberikan resiko kecelakaan dan terganggunya kesehatan yang minim. Nyaman dalam arti memberikan perasaan yang menyenangkan dan memberikan aspek beban fisiologis serta beban psikologis yang rendah. Tepat dalam arti memberikan solusi yang tepat dalam memenuhi kebutuhan manusia serta menggunakan sumber daya yang tepat. Mudah dalam arti memberikan kemudahan bagi pekerja dalam melaksanakan akttivitas dan pekerjaannya. Memberikan kepuasan dalam arti memberikan sebuah sistem yang dapat diterima dengan baik oleh manusia (Nurmianto, 2003) (Sutalaksana, 1979).

Dalam cakupannya dapat dilihat dari sudut pandang ergonomi mikro dan ergonomi makro. Ergonomi mikro menitik beratkan pada perancangan fasilitas fisik dan lingkungan fisik yang ergonomis. Ergonomi makro menitik beratkan pada aspek sosio-teknikal dalam menjembatani pengadaan fasilitas baru, agar dalam pelaksanaannya dapat berjalan dengan baik, merata, dan menyeluruh untuk seluruh lapisan masyarakat (Arturo, 2018) (Hal, 2002).

Antropometri, ialah sebuah ilmu yang mempelajari tata cara pengukuran dimensi tubuh manusia. Hasil dari pengukuran adalah data antropometri, yang akan dipergunakan dalam perancangan peralatan atau ruang untuk dipergunakan oleh manusia (Nurmianto, 2003) (Sutalaksana, 1979).

Standar kenyamanan lingkungan fisik kerja, antara lain berupa pencahayaan, ventilasi dan sirkulasi udara, yang nantinya akan mempengaruhi kinerja pekerja dalam melaksanakan 
pekerjaannya. Standar kenyamanan dan kelayakan diambil dari standar yang ditetapkan dalam buku Handbook of Ergonomic (Nurmianto, 2003) (Sutalaksana, 1979) (Silalahi dan Bennet, 1985).

Standar perancangan tata letak dan fasilitas fisik sebagai dasar dalam membuat tata letak yang memberikan keleluasaan, kenyamanan dan keamanan pekerja dalam melaksanakan pekerjaannya (Ulrich dan Epinger, 2000) (Nurmianto, 2003) (Weimer, 1993).

\section{Pembahasan}

\subsection{Aspek Ergonomi Mikro}

Pemilihan mobil yang akan direkayasa ialah mobil mobil tipe mikrobus Isuzu ELF NHR 55. Spesifikasinya sebagai berikut:
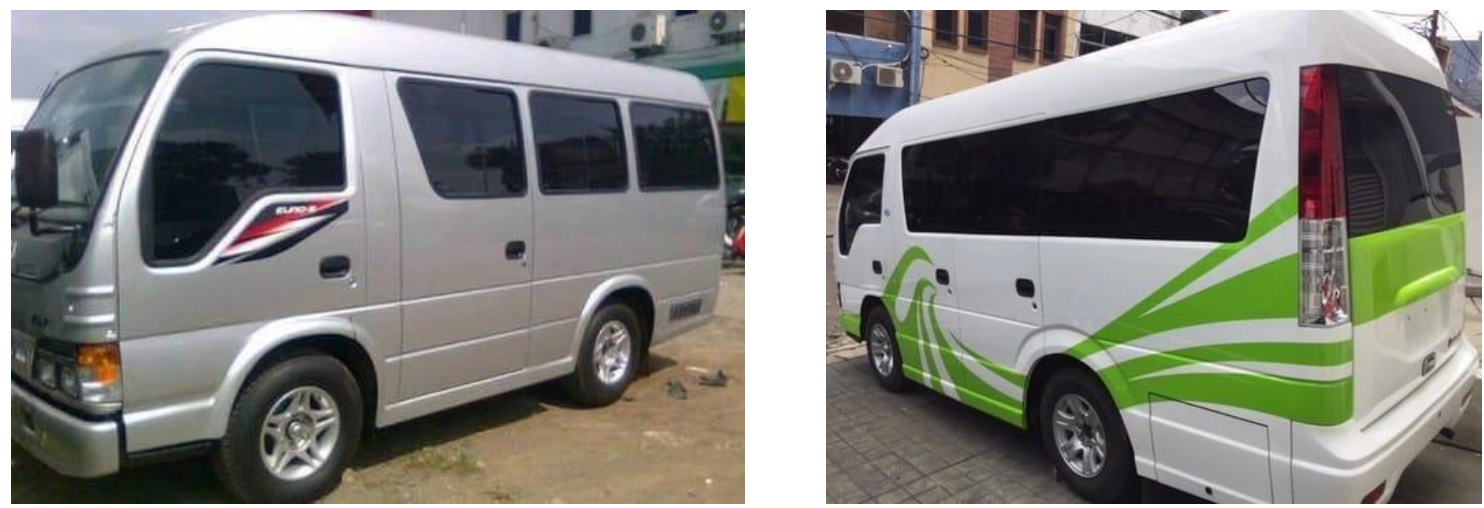

Gambar 1. Foto Mobil ELF NHR 55

\begin{tabular}{|c|c|}
\hline SPESIFIKASI & Keterangan \\
\hline \multicolumn{2}{|l|}{ DIMENSI KESELURUHAN } \\
\hline Panjang keseluruhan (mm) & 4590 \\
\hline Lebar keseluruhan (mm) & 1695 \\
\hline Tinggi keseluruhan $(\mathrm{mm})$ & 2127 \\
\hline Tinggi dari tanah $(\mathrm{mm})$ & 210 \\
\hline Jarak Poros Roda (mm) & 2,490 \\
\hline Jarak Pijak Roda Depan (mm) & 1,425 \\
\hline Jarak Pijak Roda Belakang $(\mathrm{mm})$ & 1,405 \\
\hline \multicolumn{2}{|l|}{ DIMENSI INTERIOR } \\
\hline Panjang (mm) & 3350 \\
\hline Lebar (mm) & 1550 \\
\hline Tinggi dari tanah $(\mathrm{mm})$ & 667 \\
\hline \multicolumn{2}{|l|}{ BERAT } \\
\hline Front Axle Capacity (kg) & 1,600 \\
\hline Rear Axle Capacity (kg) & 3,500 \\
\hline Curb Weight (berat kosong) (kg) & 1,470 \\
\hline Gross Vehicle Weight (berat total) (kg) & 5,100 \\
\hline
\end{tabular}

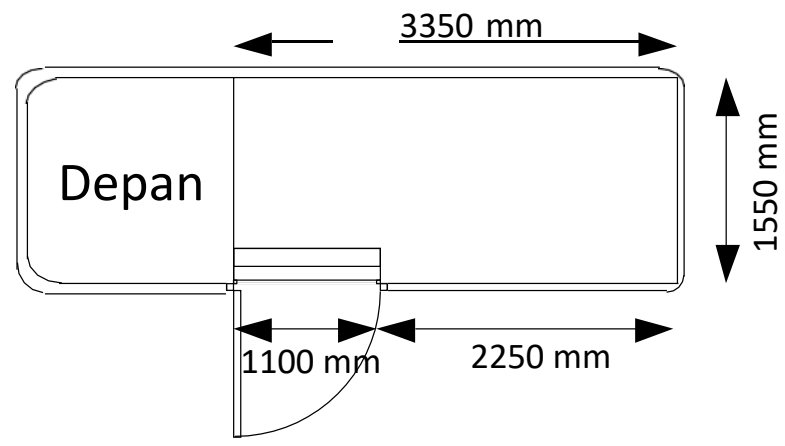

Gambar 2. Spesifikasi Mobil 
Sistem informasi manajemen untuk pengelolaan obat diberikan di bawah ini :

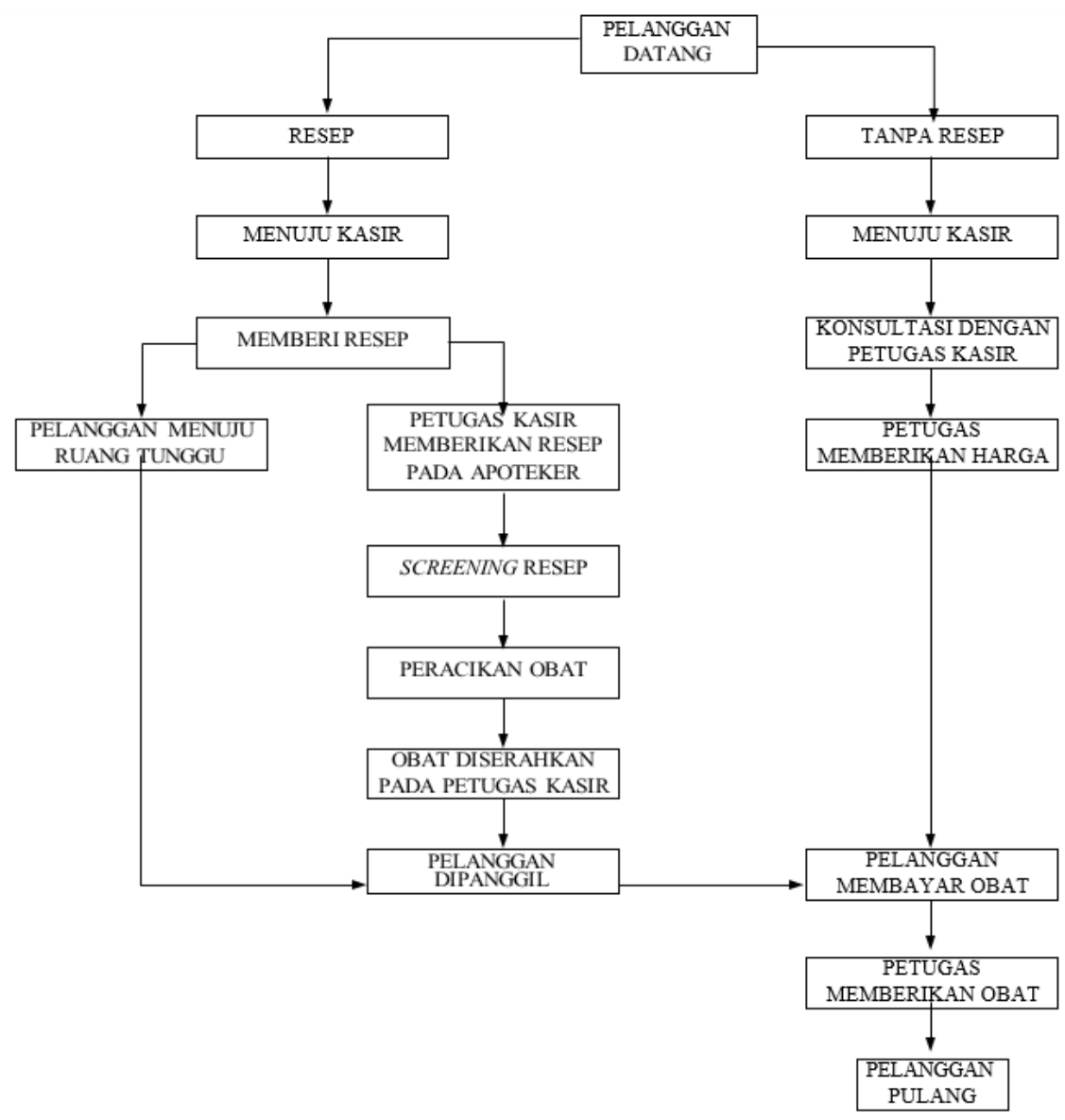

Gambar 3. Sistem Informasi Manajemen Pengelolaan Obat

Rancangan tata letak dalam ELF MHR 55, sebagai berikut :

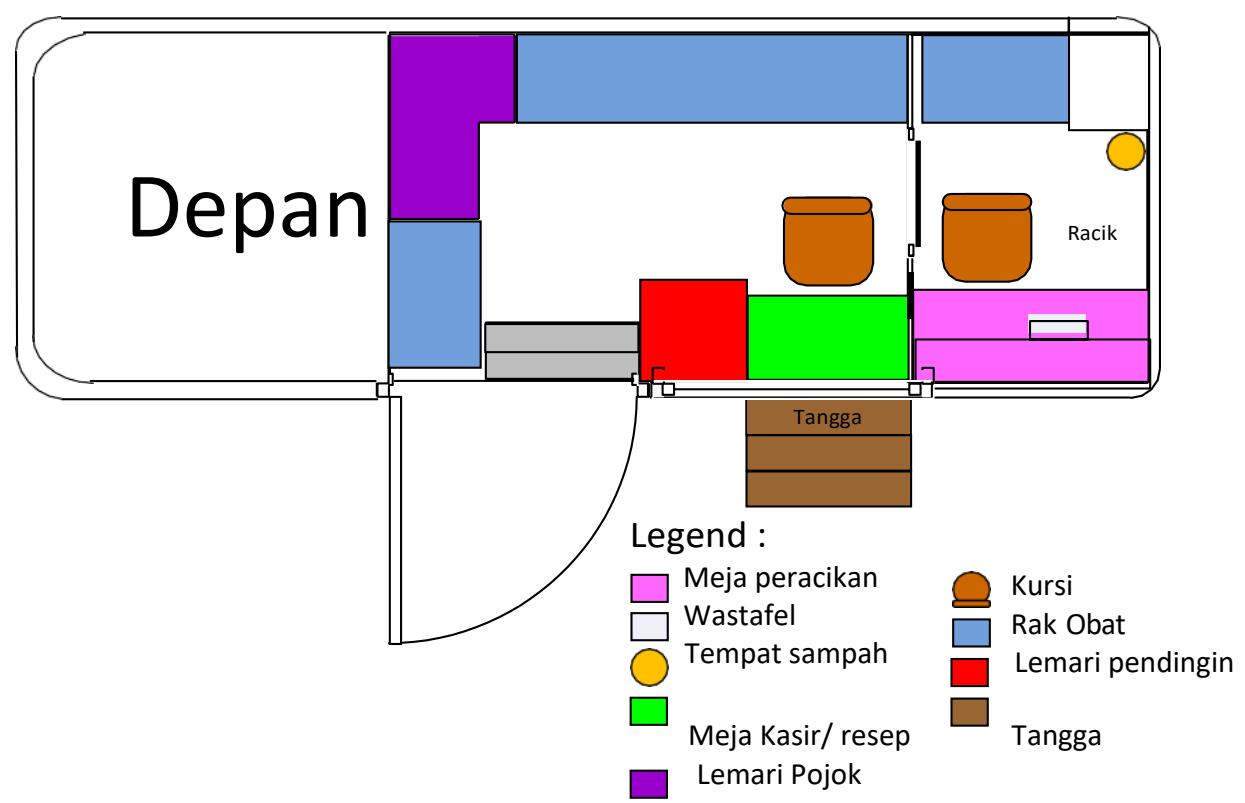

Keterangan: Genset dan APAR disimpan dalam lemari.

Gambar 4. Perancangan Tata Letak di Dalam Mobil 
Tabel 1. Fasilitas yang Disediakan Dalam Apotek Berjalan

\begin{tabular}{|c|c|c|}
\hline Gambar & Nama fasilitas dan spesifikasi & Keterangan \\
\hline & $\begin{array}{l}\text { Lemari Es } \\
\text { Jumlah: } 1 \text { buah. } \\
\text { Daya: } 70 \mathrm{~W}(220 \mathrm{~V}, 50 \mathrm{~Hz}) \\
\text { Dimensi: } 470 \times 450 \times 670 \mathrm{~mm}\end{array}$ & 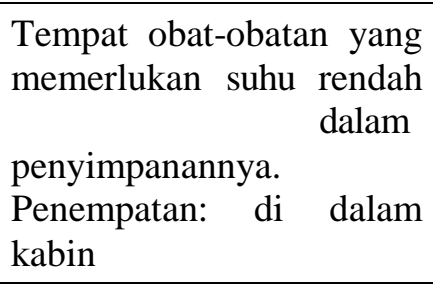 \\
\hline & $\begin{array}{l}\text { Genset } \\
\text { Daya: } 850-1000 \text { watt } \\
\text { Jumlah: } 1 \text { buah. } \\
\text { Dimensi: } 385 \times 320 \times 330 \mathrm{~mm}\end{array}$ & $\begin{array}{l}\text { Sebagai sumber daya } \\
\text { listrik. } \\
\text { Penempatan: di dalam } \\
\text { kabin, dipergunakan } \\
\text { hanya bila supply listrik } \\
\text { berkurang }\end{array}$ \\
\hline & Kursi Chitose & $\begin{array}{l}\text { Dipilih kursi yang dapat } \\
\text { dilipat, sehingga tidak } \\
\text { memakan tempatpada saat } \\
\text { tidak dieprgunakan. } \\
\text { Penempatan: di dalam } \\
\text { kabin }\end{array}$ \\
\hline & $\begin{array}{l}\text { APAR } \\
\text { Jenis: Serbuk Kimia (Dry } \\
\text { Chemical Powder) } \\
\text { Kapasitas: } 5 \mathrm{Kg}\end{array}$ & $\begin{array}{l}\text { Untuk pencegahan } \\
\text { kebakaran. } \\
\text { Penempatan: di dalam } \\
\text { kabin }\end{array}$ \\
\hline
\end{tabular}

Perancangan fasilitas fisik didasarkan pada dimensi obat-obatan, antropometri (mudah dalam penjangkauan obat-obatan), dan keterbatasan area dalam kabin mobil.

Untuk fasilitas peracikan, dirancang meja sekaligus lemari untuk menyimpan peralatan yang digunakan untuk meracik obat.
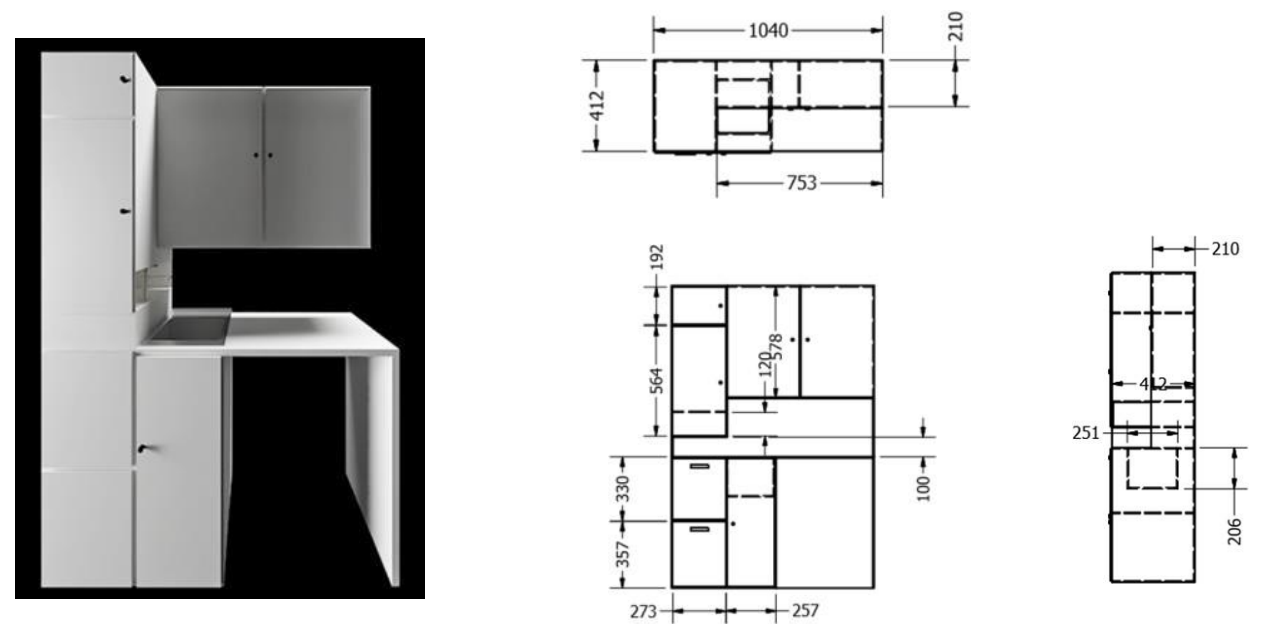

Gambar 5. Gambar dan Spesifikasi Rak/Meja Peracikan 

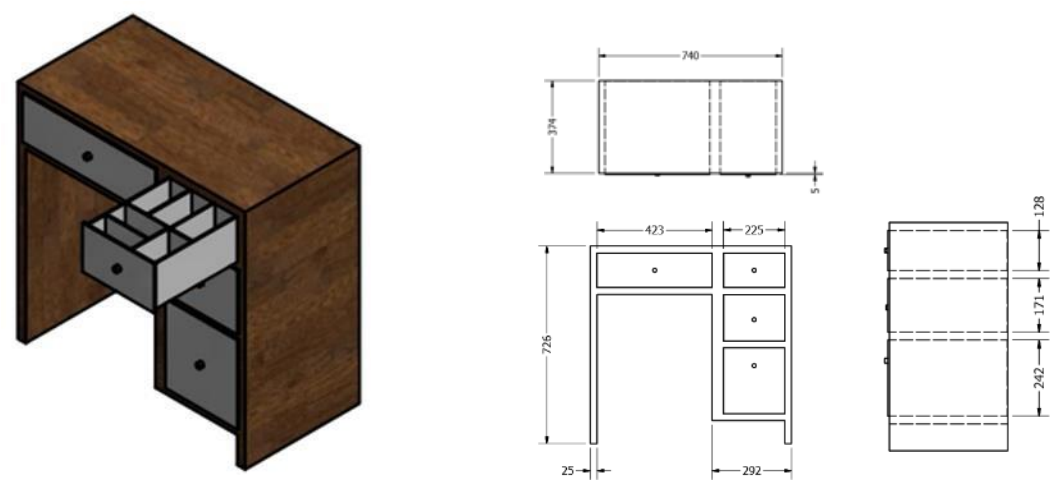

Gambar 6. Gambar Dan Spesifikasi Meja Kasir

Untuk fasilitas lemari penyimpanan obat, dirancang sebagai berikut :
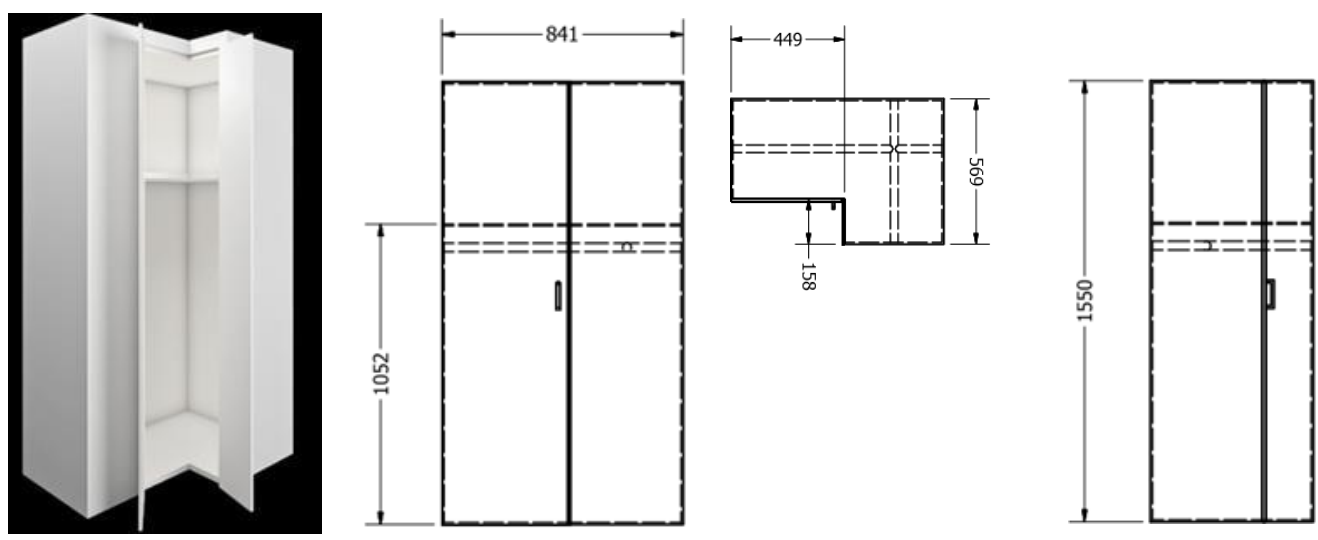

Gambar 7. Gambar dan Spesifikasi Lemari Penyimpanan Obat Pojok
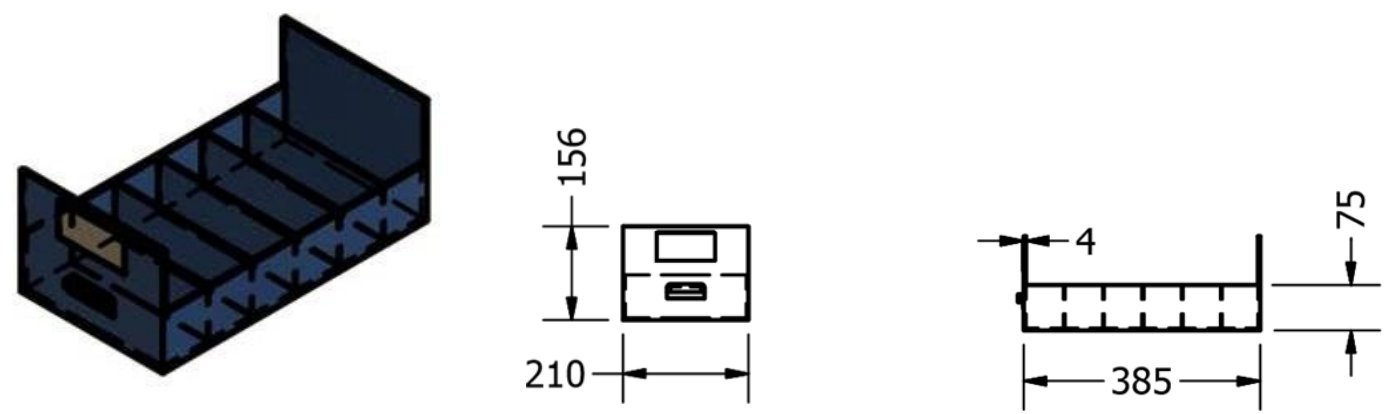

Gambar 8. Gambar dan Spesifikasi Container Penyimpanan Obat yang Akan Disimpan Dalam Rak 

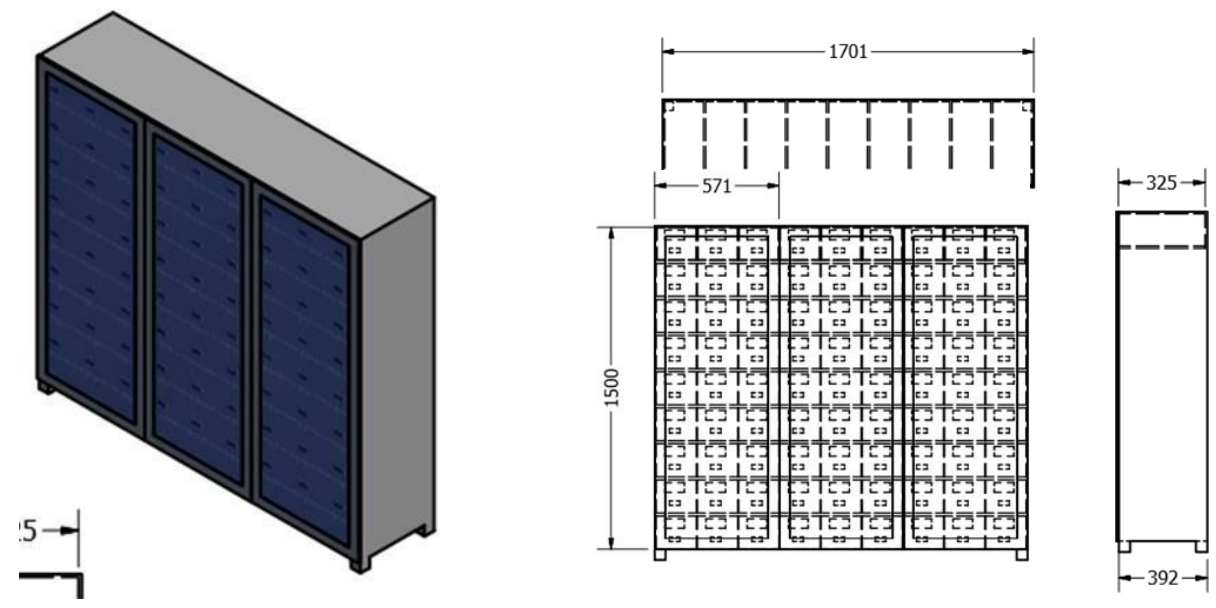

Gambar 9. Gambar dan Spesifikasi Rak Penyimpanan Obat
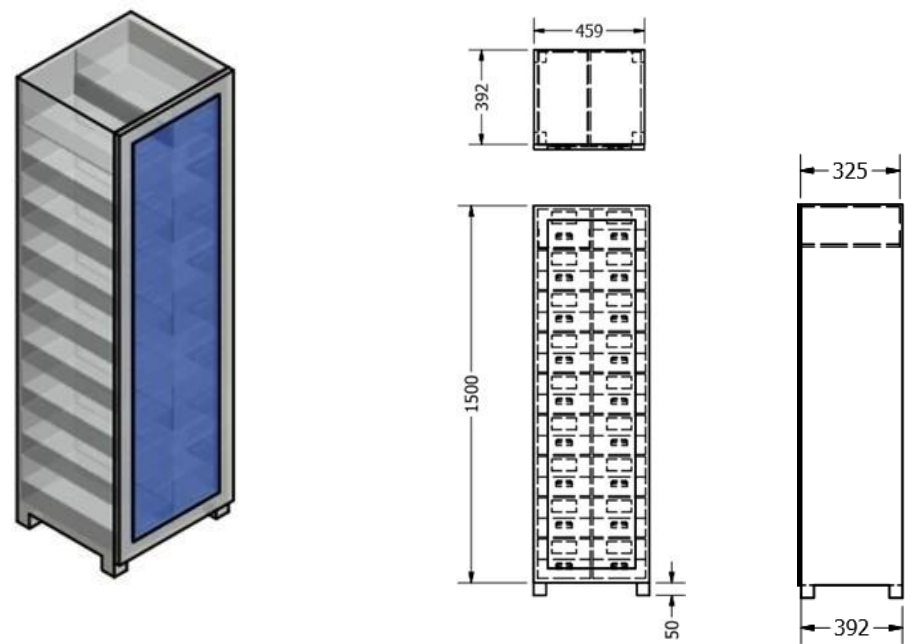

Gambar 10. Gambar dan Spesifikasi Rak Kecil 1
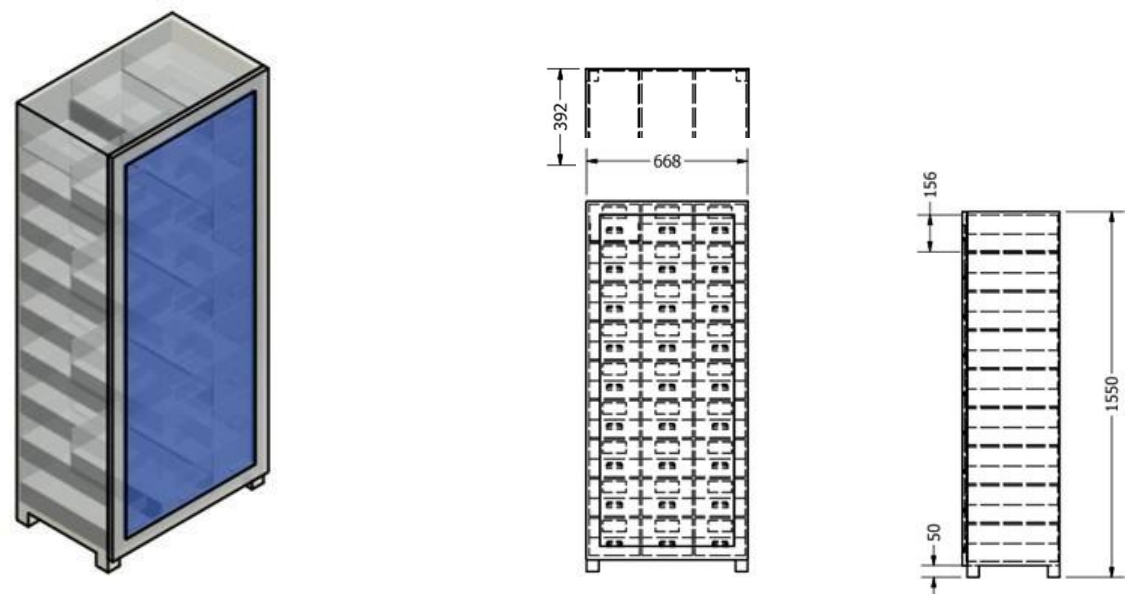

Gambar 11. Gambar dan Spesifikasi Rak Kecil 2 

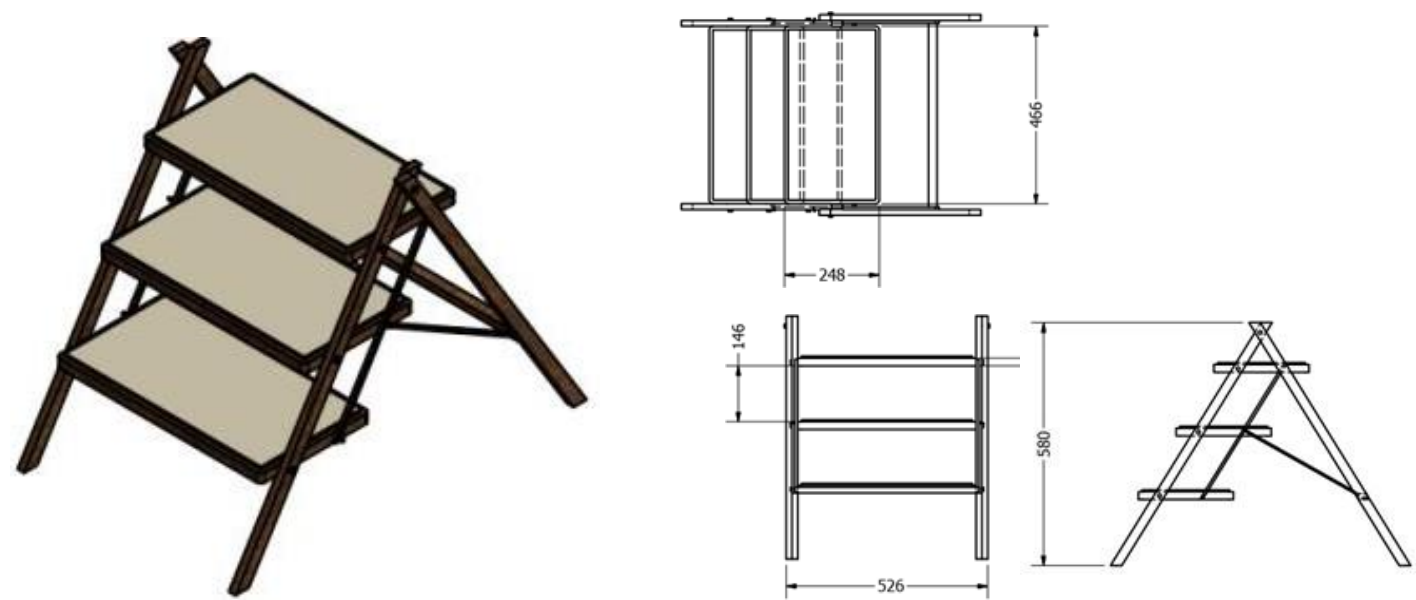

Gambar 12. Gambar dan Spesifikasi Tangga

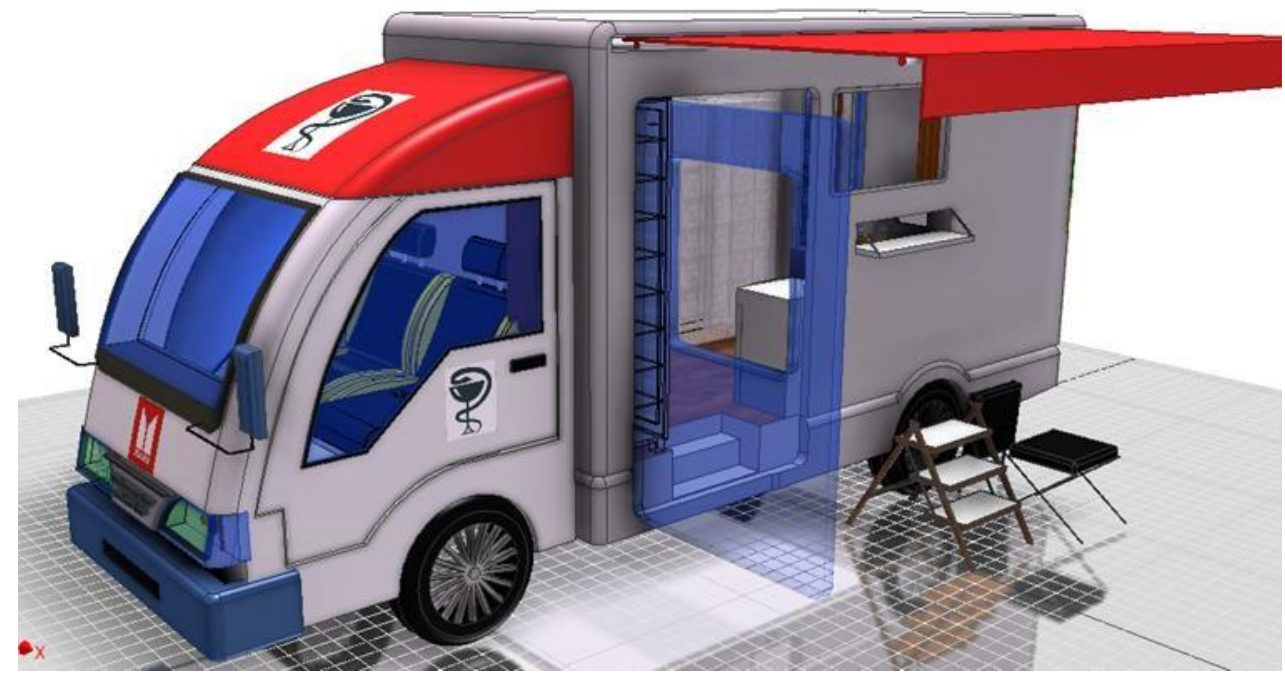

Gambar 13. Gambar 3D Apotek berjalan

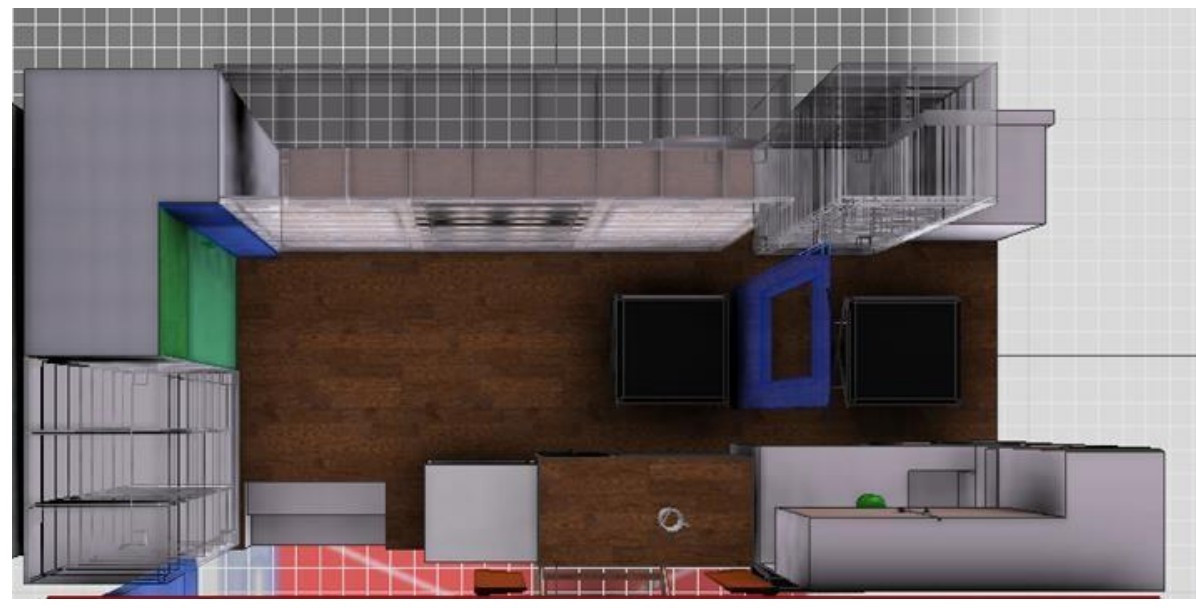

Gambar 14. Gambar 3D Tampak Dalam Apotek Berjalan 
Dalam aspek penerangan, penetapan titik lampu didasarkan pada aspek intensitas penerangan yang cukup pada setiap area. Titik lampu diberikan pada 2 tempat, yaitu:

1. Di dalam tiap slot lemari. Tujuannya ialah agar obat-obatan dapat terlihat dengan jelas di dalam lemari.

2. Di area tengah kabin, yang menjadi penerangan area kabin.

3. Penerangan khusus di atas meja racik.

Sumber energi listrik didapatkan dari panel surya yang dipasang di atas atap dan sebagai cadangan energi disediakan genset.

Untuk ventilasi dan sirkulasi udara, disediakan lubang khusus ventilasi di atas atap. Lubang loket penyerahan obat juga selalu terbuka pada saat operasional, yang juga sebagai ventilator udara.

\subsection{Aspek Manajemen Informasi Obat-obatan}

Untuk Sistem Informasi Manajemen dirancang sistem sebagai berikut :

1. Obat-obat disimpan dalam rak yang diberikan kode pada label yang ditempelkan dalam setiap rak dan container.

2. Obat-obatan dikelompokan dalam abjad. Terkecuali obat-obatan yang perlu disimpan dalam lemari pendingin dan obat-obatan khusus (psikotropia, dst).

3. Kartu stock, untuk mendapatkan informasi ketersediaan obat dalam apotek berjalan. Selain diberikan dalam program komputer juga dalam manual.

\begin{tabular}{|c|c|c|c|c|}
\hline \multicolumn{5}{|c|}{ KARTU STOCK OBAT } \\
\hline $\begin{array}{c}\text { Golongan } \\
\text { Obat }\end{array}$ & Jenis Obat & Nama Obat & Packing & Bentuk Obat \\
\hline & & & $\begin{array}{ll}\bigcirc & \text { Botol } \\
\bigcirc & \text { Strip } \\
\bigcirc & \text { Dus/plastik }\end{array}$ & $\begin{array}{ll}\bigcirc & \text { Cairan } \\
\bigcirc & \text { Bubuk } \\
\bigcirc & \text { Tablet } \\
\bigcirc & \text { Kaplet } \\
\bigcirc & \text { Kapsul }\end{array}$ \\
\hline Tanggal & $\begin{array}{c}\text { Jumlah } \\
\text { Barang Masuk }\end{array}$ & $\begin{array}{c}\text { Jumlah } \\
\text { Barang Keluar }\end{array}$ & Sisa Obat & Keterangan \\
\hline & & & & \\
\hline & & & & \\
\hline & & & & \\
\hline & & & & \\
\hline & & & & \\
\hline & & & & \\
\hline & & & & \\
\hline
\end{tabular}

Gambar 15. Contoh Kartu Stock

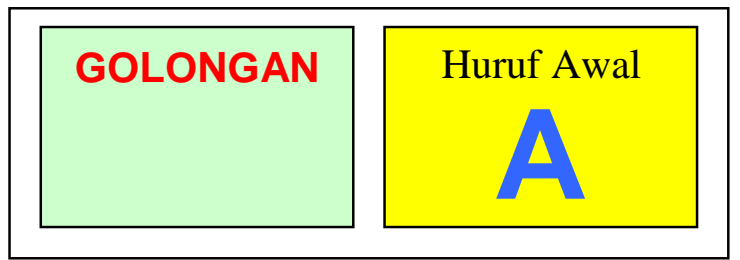

Gambar 16. Contoh Label yang ditempel dalam lemari obat 
Untuk memudahkan pencarian obat, dirancang label obat yang ditempatkan pada setiap lemari obat. Label obat dirancang sederhana dan mudah untuk dibaca. Untuk golongan diberikan warna huruf merah berdasar hijau. Sedangkan huruf awal dari obat yang diurut dalam abjad diberikan warna biru berdasar kuning. Konfigurasi kedua warna ini didasarkan pada efektivitas penglihatan berdasarkan kekontrasan image-background.

\subsection{Aspek Ergonomi Makro}

Secara ergonomi makro, keberadaan fasilitas apotek berjalan ini mempunyai berbagai keuntungan, antara lain:

a. Masyarakat di pedesaan tidak perlu jauh-jauh ke kota untuk mendapatkan obat-obatan yang dibutuhkan, dimana obat-obatan tersebut tidak dimiliki oleh puskesmas di daerahnya.

b. Masyarakat perkotaan yang berkunjung ke pedesaan, misalnya untuk kunjungan kerja atau rekreasi, bilamana sakit atau memerluikan obat-obatan, dapat memperolehnya di pedesaan. Mereka tidak perlu balik lagi ke kota untuk mendapatkan obat-obatan.

c. Dapat membantu instansi penanggulangan musibah bencana alam atau tempat pengungsian dalam penyediaan obat-obatan bagi masyarakat yang terkena musibah.

d. Pemerataan atau jangkauan yang lebih luas kepada masyarakat untuk memperoleh jaminan kesehatan, dalam hal ini ketersediaan obat-obatan, merupakan salah satu pengamalan sila ke5 Pancasila, yaitu Keadilan sosial bagi seluruh rakyat Indonesia.

\section{Kesimpulan}

Dengan belum meratanya toko obat sampai ke pelosok daerah, membuat moda apotek berjalan ini sangatlah diperlukan. Orang di daerah tidak perlu lagi untuk jauh pergi ke kota besar untuk mendapatkan obat yang diperlukan.

Perancangan kabin apotek berjalan dibuat dengan tujuan agar obat-obatan yang dibawa dapat tersimpan dengan baik dan aman. Selain itu, pekerja yang bekerja di dalam kabin apotek berjalan dapat cukup leluasa dalam mengelola obat-obatan dan meracik obat yang diperlukan. Selain itu disediakan tempat/loket untuk menerima pembeli/resep dan penyerahan obat kepada pembeli.

Sumber energi listrik yang digunakan untuk lemari pendingin obat dan penerangan didapatkan dari panel surya yang dipasang pada atap dan sebagai emergency digunakan genset.

Ventilasi dan sirkulasi tersedia dalam ruangan kabin apotek berjalan agar udara dalam kabin bisa selalu segar dan tidak panas.

Sistem pencatatan obat-obatan agar mudah ditemukan melalui label dengan huruf dan warna yang kontras. Sedangkan pencatatan stock obat dilakukan melalui sistem komputer dan manual (kartu stock).

Dengan dirancangnya apotek berjalan ini dapat memudahkan kebutuhan penduduk di daerah dan di pedesaan yang belum mendapatkan stock obat yang cukup dan beragam dibandingkan di kota besar menjadi terpenuhi. Penduduk di daerah dapat lebih cepat dan mudah mendapatkan obat yang dibutuhkan. Dengan kata lain, kesembuhan orang sakit juga lebih terjamin dan lebih luas sampai ke pelosok pedesaan. Inilah bentuk atau iklim makro ergonomi yang baik tercipta melalui tersedianya apotek berjalan.

Jadi, dalam perkembangan ergonomi, dulu tidak ada istilah ergonomi mikro dan ergonomi makro. Baru pada tahun 1984, seorang ilmuwan dibidang ergonomi yang bernama Prof. Hall Hendrick mencetuskan aspek ergonomi makro. Hal yang melatarbelakangi munculnya ergonomi makro ialah karena perkembangan teknologi dan peradaban manusia yang sudah demikian kompleks.

Salah satu aspek dari ergonomi makro ialah, sejalan dengan perkembangan teknologi di dunia ini menjadikan pencemaran dan polusi lingkungan menjadi semakin parah. Sejalan dengan itu, penyakit juga semakin banyak jenis dan macamnya. Keberadaan industri-industri tidak diijinkan di perkotaan, sehingga mereka berdiri di pedesaan dan daerah yang jauh dari perkotaan. Industri tidak dapat 
terpelas dengan limbah. Limbah dan pencemaran lingkungan menjadikan orang di pedesaan menjadi rentan terhadap penyakit. Disisi lain, fasilitas kesehatan di pedesaan belum lengkap keberadaannya dibandingkan dengan diperkotaan. Sehingga keberadaan fasilitas yang dirancang ini bisa menjembatani kebutuhan masyarakat pedesaan atau terpencil untuk mendapatkan pasokan obatobatan.

\section{Daftar Pustaka}

Arturo Realyvásquez (2018), Macroergonomics for Manufacturing Systems An Evaluation Approach, Springer International Publishing, Switzerland.

Hal W. Hendrick (2002), Macroergonomics Theory, Methods and Applications, Lawrence Erlbaum Associates Publishers, New Jersey, London.

Nurmianto, Eko (2003), Ergonomi : Konsep Dasar dan Aplikasinya, Edisi Pertama, Guna Widya, Surabaya.

Silalahi, B. Rumondang, N.B Bennet (1985), Manajemen Kesehatan dan Keselamatan Kerja, Seri Manajemen, Cetakan Pertama, Institut Pendidikan dan Pembinaan Manajemen (IPPM), Jakarta.

Suma'mur P.K. (1987), Kesehatan dan Keselamatan Kerja dan Pencegahan Kecelakaan, Cetakan ke-3, CV. Haji Masagung, Jakarta.

Sutalaksana, Iftikar Z., Ruhana Anggawisastra, John H. Tjakraatmadja (1979), Teknik Tata Cara Kerja, Departemen TI - ITB.

Ulrich K.T., Epinger S.D. (2000), Product Design and Devolopment, 2nd edition, McGraw-Hill, Singapore.

Weimer Don, Ph. D. (1993), Handbook of Ergonomic and Human Factors Tables, Prentice Hall, Emglewood Cliffs, New Jersey. 